\title{
Cardiac and Respiratory Activity in Relation to Gestation and Sleep States in Newborn Infants
}

\author{
BIJAN SIASSI, JOAN E. HODGMAN, LUIS CABAL, AND EDWARD H. HON
}

Departments of Pediatrics, Obstetrics and Gynecology, University of Southern California School of Medicine, and the Newborn Division and Section of Perinatal Medicine, Los Angeles County-University of Southern California Medical Center, Los Angeles, California, USA

\section{Summary}

In order to provide normative values of heart and respiratory rate and variability in relation to gestation and sleep states, 32 neonates who were free from cardiopulmonary disease were studied during the 1st-6 day of life. The infants were grouped as follows: group A, 9 infants with gestational ages of 27-33 wk; group B, 14 infants with gestational ages of 34-36 wk; and group C, 9 infants with gestational ages of 37-40 wk. Recordings and observations were made during a 1-hr postprandial nap. During active sleep (AS) and quiet sleep (QS), heart rate, short-term and long-term variability of the heart rate, respiratory rate, variability of the respiratory rate and apnea density were measured. Both the long- and short-term heart rate variability was less in preterm infants (group A) than the less immature or full term infants (groups $B$ and $C, P<0.01$ ). Breath-to-breath respiratory variability was not significantly affected by gestational age, whereas percent duration of apnea was less in full term (group $\mathrm{C}$ ) than the preterm groups of infants during quiet sleep (groups $A$ and $B, P$ $<0.05$ ). There was no significant difference between baseline heart rate, short-term heart rate variability, and respiratory rate during AS and QS states at any given gestational age. Long-term variations in heart rate, breath-to-breath respiratory variability, and percent duration of apnea were significantly less in QS in comparison to AS at each gestational age group $(P<0.01)$.

\section{Speculation}

Systematic monitoring of newborn infants by the techniques presented in this report would further define normal cardiorespiratory functions in relation to maturity and sleep states. Application of these techniques to the study of the distressed newborn should provide an early indication of morbidity and recovery from disease.

Dynamic alterations in cardiac and respiratory activity are dependent on the maturity and state of "sleep-wakefulness" both in the fetus and the newborn infant $(2,17,19)$. These dynamic events are also influenced by the state of health and disease in the fetus and newborn $(2,13)$.

Cardiac rate variability (beat-to-beat interval differences) is an inherent characteristic of the normal heart rate. Measurement of heart rate variability in the fetus is of value in the management of labor and delivery $(5,13)$. Loss of variability in the fetus has been associated with an increased incidence of mortality from the respiratory distress syndrome in preterm infants (7). A fixed heart rate in premature infants with respiratory distress syndrome has been associated with a poor prognosis (16). Methods for computer analysis of instantaneous changes in cardiac and respiratory action in the newborn have been described that permit detailed analysis of neonatal records $(18,19)$, however, the state of sleep or wakefulness was not taken into account in these studies.

The purposes of this report are 1) to describe electronic techniques that have been developed for biophysical evaluation of the newborn and 2) to provide preliminary normative data on the effect of maturity and sleep states on newborn cardiac and respiratory function.

\section{PATIENTS AND PROCEDURES}

Thirty-two neonates, 18 male and 14 female, who were free from cardiopulmonary disease, were studied during the 1 st-6th day of life. Written consent was obtained from the mother before study. The infants were grouped as follows: group A, 9 infants with gestational age of 27-33 wk; group B, 14 infants with gestational age of 34-36 wk; and group C, which included 9 infants with gestational age of 37-40 wk (Table 1). All observations and recordings were made while the subject was lying naked in an intensive care incubator with a servo-control mechanism to maintain skin temperature at $36.5^{\circ} \mathrm{C}$. The infants were studied after either the 8:00 AM or 12:00 noon feedings. After the attachment of the appropriate leads and sensors and a 15-min stabilization period, each infant was studied for $1 \mathrm{hr}$.

\section{RECORDING PROCEDURE}

Electrocardiographic signals were obtained from bipolar chest leads. Respiration was recorded by monitoring expired $\mathrm{CO}_{2}$ concentration that was sampled through a small polyethylene tube attached to the infant's nostril. Skin and rectal temperatures were obtained with temperature sensors (Yellow Springs Instrument Co.). Three infants had an indwelling arterial catheter for clinical management, through which continuous arterial pressure was recorded using a Statham Db 37 strain gauge transducer.

Two multichannel strip chart recorders running at different paper speeds ( 25 and $0.5 \mathrm{~mm} / \mathrm{sec}$ ) were used. In addition, the data were also recorded on magnetic tape for later detailed study and computer analysis. During the study, the infants were observed continuously for rapid eye movements and somatic activity and the observations were recorded on the strip charts and magnetic tape with a specially designed code generator.

The electrocardiogram, respiration wave form, and behavioral observation signals were recorded at the higher paper speed of 25 $\mathrm{mm} / \mathrm{sec}$ (Beckman Dynograph Model 504D) and on analog tape recorder (Ampex Model PR500). Beat-to-beat heart rate, beat-tobeat variations ( $R-R$ interval differences) respirogram, behavioral observations, breath-to-breath respiratory rate, arterial pressure,

Table 1. Clinical data of 32 newborn infants studied ${ }^{1}$

\begin{tabular}{lccc}
\hline & Group A & Group B & Group C \\
\hline Number & 9 & & 9 \\
Age at study (days) & $4.0(2-6)$ & $3.5(1-6)$ & $4.0(2-6)$ \\
Gestation (wk) & $30.5(27-33)$ & $35(34-36)$ & $38.5(37-40)$ \\
Birth wt (g) & $1525(760-$ & $2109(1340-$ & $2687(1700-$ \\
& $2160)$ & $3320)$ & $4060)$ \\
\hline
\end{tabular}

\footnotetext{
${ }^{1}$ Range of values expressed in parentheses.
} 
and temperature readings were recorded at the slower paper speed of $0.5 \mathrm{~mm} / \mathrm{sec}$ (Brush Mark 200). Much of the data on this slower record were reduced with specially designed electronic equipment, viz a beat-to-beat cardiotachometer for heart rate, an interval differentiator for $\mathrm{R}-\mathrm{R}$ interval differences, and breath-to-breath tachometer to convert breath intervals to rate per minute. The data recorded on both strip charts and the analog magnetic tape were cross-correlated with the aid of a common time code signal.

\section{DATA COLLECTIONS AND ANALYSIS}

The records were divided into 1-min epochs. Each epoch was coded according to the behavioral observations, as follows: 1) active sleep (AS): presence of rapid eye movements + frequent limb movements + closed eyes. 2) quiet sleep (QS): absent rapid eye movements + absent limb movements except for episodic events + closed eyes. 3 ) "awake" states: crying or open eyes.

The epochs that did not fit any of the above classifications were labeled "transitional" state. Respiratory rate for each 1-min epoch was directly measured by visual inspection of the polygraphic records. Each breath-to-breath interval was converted to an instantaneous respiratory rate. Respiratory variability was determined for each min by the difference between the fastest and slowest instantaneous rate in each epoch. The amount of apnea was obtained using a modification of the technique used by Miller et al (10). All periods of no respiratory activity greater than $3 \mathrm{sec}$ were summed, divided by the duration of the epoch $(60 \mathrm{sec})$, and multiplied by $100(\mathrm{~A} / \mathrm{D} \%)$. Neonatal heart rate variability was determined with techniques described by Yeh et al (22). The electrocardiogram data were played back from the analog magnetic tape, the R-R intervals digitized, calculated in milliseconds, and stored on magnetic tape. Mean heart rate and SD were calculated from the R-R intervals for each epoch. The interval index (II) defined as the SD of R-R intervals over the mean $R-R$ interval was calculated for each $1-\min$ epoch. This figure represents the long-term variability in heart rate occurring at 3-5 cycles/min. The differential index (DI) was defined as the SD of differences between successive $\mathbf{R}-\mathbf{R}$ intervals and was computed as a measure of beat-to-beat or short-term heart rate variability. All data obtained for each epoch were punched on 80 column cards. A total of 2182 epochs were then analyzed with the aid of an IBM 360 computer. Statistical analysis included one-way analysis of variance and Student's $t$ test for independent means to detect differences between the groups and Student's $t$ test for paired values to detect differences between QS and AS.

\section{RESULTS}

Ninety-two percent of epochs analyzed were classified as either AS or QS (32\%). The term infants, group C, spent more time in QS (36\%) and less in AS (46\%). In the present study, cardiorespiratory measurements were made during these two sleep states (Table 2). Sleep states strongly influenced the event-to-event variations of the heart and respiratory activity, as could be appreciated by inspection of the polygraph record (Fig. 1).

Table 2. Heart rate, respiratory rate, and indices of heart and respiratory rate variability during quiet and active sleep states in 33 newborn infants

\begin{tabular}{lcccccc}
\hline & $\begin{array}{c}\text { Heart rate } \\
\text { beats } / \text { min }\end{array}$ & Interval index & Differential index & $\begin{array}{c}\text { Respiratory rate } \\
\text { breaths/min }\end{array}$ & $\begin{array}{c}\text { Breath-to-breath respira- } \\
\text { tory variability/min }\end{array}$ & A/D $^{3}{ }^{3}$ \\
\hline QS & $139 \pm 15.1^{4}$ & $3.2 \pm 1.52$ & $7.6 \pm 3.72$ & $44 \pm 12.9$ & $38 \pm 29$ & $9 \pm 16.3$ \\
AS & $141 \pm 14.1$ & $4.2 \pm 1.68$ & $7.6 \pm 3.06$ & $45 \pm 13.1$ & $63 \pm 25$ & $15 \pm 18.4$ \\
$P$ value $^{5}$ & $\mathrm{NS}^{6}$ & $<0.01$ & NS & NS & $<0.01$ & $<0.01$ \\
\hline
\end{tabular}

${ }^{1}$ Interval index is defined as the coefficient of variation of $R-R$ intervals $\frac{\text { SD of } R-R \text { intervals }}{\text { Mean } R-R \text { interval }}$ during 1 min, representing the long-term heart rate variability.

${ }^{2}$ Differential index is defined as the SD of differences between successive R-R intervals representing short-term variability of the heart rate.

${ }^{3} \mathrm{~A} / \mathrm{D} \%=$ summed duration of no respiration greater than $3 \mathrm{sec}$ expressed as fraction of $60 \mathrm{sec}$ in each epoch.

${ }^{4}$ Values are expressed as mean $\pm \mathrm{SD}$.

${ }^{5}$ Pair $t$ statistics.

${ }^{6} \mathrm{NS}=$ not significant.

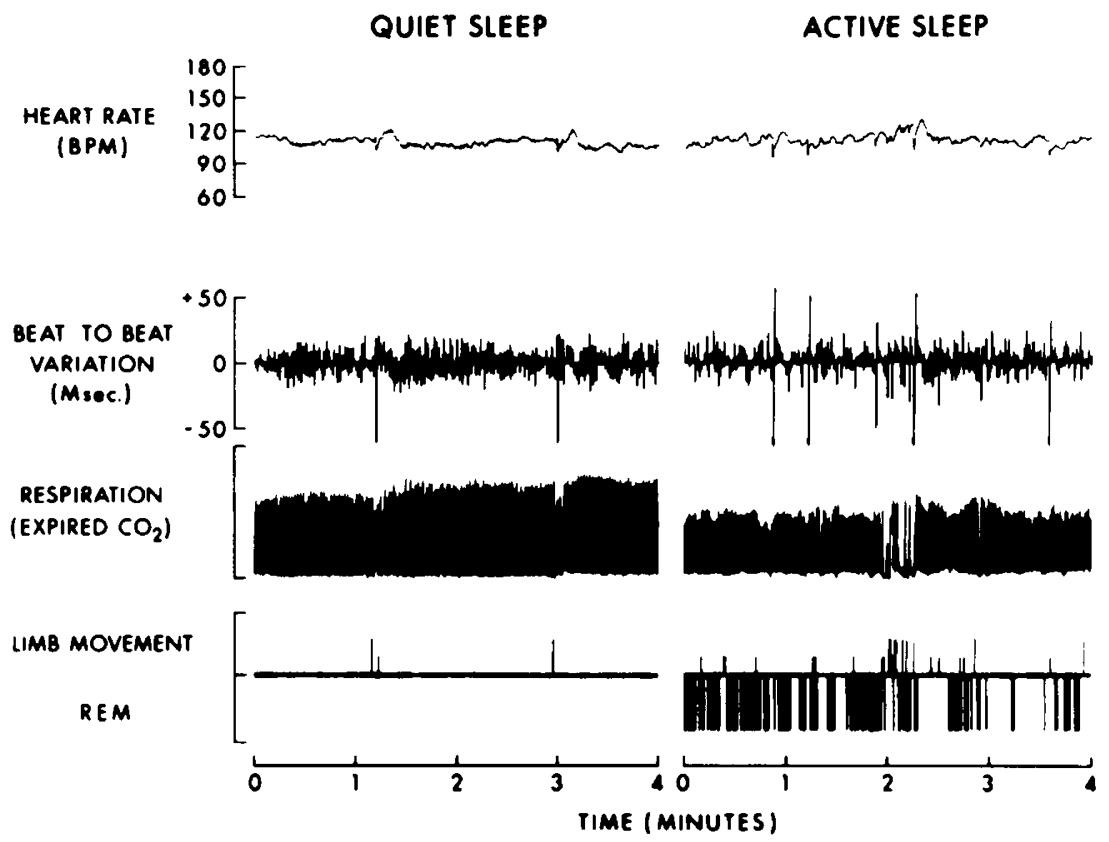

Fig. 1. Portions from polygraph record at paper speed of $0.5 \mathrm{~mm} / \mathrm{sec}$ in a 36 -wk of gestation premature infant (birth wt. $=2340 \mathrm{~g}$ ) recorded at 3 days of age. 
Table 3. Heart rate, respiratory rate, and indices of heart rate and respiratory rate variability in preterm (groups $A$ and $B$ ) and full term (group C) newborn infants

\begin{tabular}{|c|c|c|c|c|c|c|}
\hline & $\begin{array}{l}\text { Heart rate } \\
\text { beats } / \mathrm{min}\end{array}$ & Interval index' & Differential index ${ }^{2}$ & $\begin{array}{c}\text { Respiratory rate } \\
\text { breaths/min }\end{array}$ & $\begin{array}{c}\text { Breath-to-breath respira- } \\
\text { tory variability/min }\end{array}$ & $\mathrm{A} / \mathrm{D} \%^{3}$ \\
\hline \multicolumn{7}{|c|}{ Group A (27-33wk) } \\
\hline QS & $153 \pm 12.8^{4}$ & $1.9 \pm 0.25$ & $4.1 \pm 0.78$ & $44 \pm 12.0$ & $43 \pm 32$ & $9 \pm 6.0$ \\
\hline AS & $155 \pm 10.6$ & $2.8 \pm 0.36$ & $4.9 \pm 1.1$ & $45 \pm 10.2$ & $59 \pm 39$ & $12 \pm 8.6$ \\
\hline$P$ value & NS & $<0.01$ & NS & NS & $<0.01$ & $<0.01$ \\
\hline \multicolumn{7}{|c|}{ Group B (34-36wk) } \\
\hline QS & $137 \pm 10.7$ & $3.8 \pm 1.55$ & $9.6 \pm 4.05$ & $39 \pm 12.3$ & $43 \pm 29$ & $12 \pm 14.9$ \\
\hline AS & $141 \pm 8.6$ & $4.6 \pm 1.66$ & $9.0 \pm 3.24$ & $41 \pm 12.3$ & $63 \pm 28$ & $18 \pm 18.0$ \\
\hline$P$ value & NS & $<0.01$ & NS & NS & $<0.01$ & $<0.01$ \\
\hline \multicolumn{7}{|c|}{ Group C $(37-40 w k)$} \\
\hline QS & $130 \pm 12.0$ & $3.5 \pm 1.46$ & $8.2 \pm 2.40$ & $36 \pm 13.0$ & $48 \pm 28$ & $4 \pm 4.8$ \\
\hline AS & $132 \pm 11.9$ & $4.8 \pm 1.80$ & $8.3 \pm 2.52$ & $35 \pm 14.7$ & $72 \pm 35$ & $13 \pm 8.8$ \\
\hline$P$ value & NS & $<0.01$ & NS & NS & $<0.01$ & $<0.01$ \\
\hline
\end{tabular}

${ }^{1}$ Same as Table 2.

${ }^{2}$ Same as Table 2.

: Same as Table 2.

${ }^{4}$ Values are expressed as mean $\pm \mathrm{SD}$.

" Paired $t$ statistics.
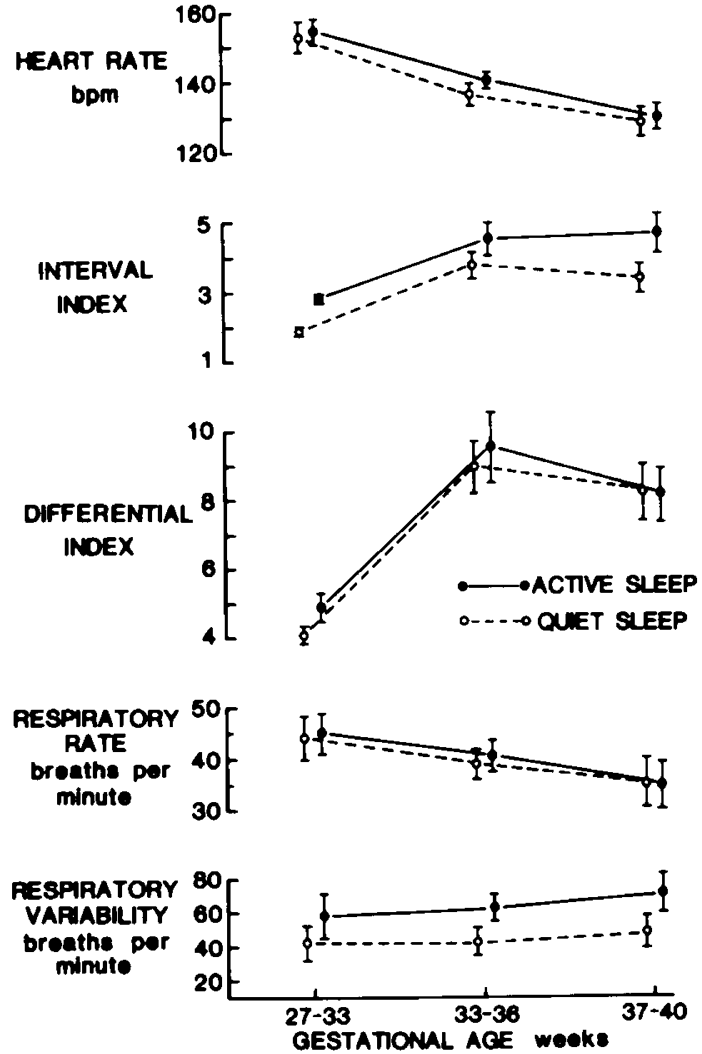

Fig. 2. Shows heart rate, interval index, differential index, respiratory rate, breath-to-breath respiratory variability for infants in group A (27-33 wk), group B (34-36 wk), and group C (37-40wk). The data for QS and AS are plotted separately. The data are expressed as mean \pm SEM.

\section{BASELINE HEART RATE AND RESPIRATORY RATE}

The average heart rate and respiratory rate decreased with increasing maturity as measured by gestational age (Table 3 and Fig. 2). Heart rate averaged 141 beats/min during AS and 139 beats/min during $\mathrm{QS}$ periods. There was no significant difference between baseline heart rate or respiratory rate during AS and QS states at any given gestational age (Table 2 and Fig. 2).

\section{VARIABILITY OF HEART RATE AND RESPIRATORY RATE}

The long-term heart rate variability (II) was less in small preterm infants (group A) than the less immature or full term infants during both QS or AS (groups B and C, $P<0.01$ ). Similarly, the short-term heart rate variability (DI) was less in preterm infants (group $A$ ) than the less immature or full term infants during QS or AS (groups B and C $P<0.01$ ). There was no significant difference in heart rate variability between groups $B$ and $C$. Breath-to-breath respiratory variability was not significantly affected by gestational age, whereas percent duration of apnea was less in full term (group $C$ ) than the preterm groups of infants during $\mathrm{QS}$ (groups $\mathrm{A}$ and $\mathrm{B}, P<0.05$ ). Long-term variations in heart rate (II) were significantly less during QS in comparison with AS state for all infants and for each gestational age group $(P<0.01)$. There was no significant difference in shortterm heart rate variability (DI) between $Q S$ and AS states. Variation in breath-to-breath respiratory rate and the percent of apnea $(\mathrm{A} / \mathrm{D} \%)$ were significantly less in QS in comparison with AS for all infants and at any gestational age $(P<0.01)$ (Tables 2 and 3 and Fig. 2).

\section{DISCUSSION}

Variability of heart rate is characteristically present in the healthy fetus and newborn infant $(5,18)$. At least two components of heart rate variability have been identified. Short-term or beatto-beat variability occurs at the frequency of the heart rate. whereas long-term variability occurs at 3-6 cycles $/ \mathrm{min}$. Yeh et al. (22) have used coefficient of variation of $R-R$ interval differences (DI) in order to quantitate beat-to-beat heart rate variability and the coefficient of variations of $R-R$ intervals during each epoch (II) as a measure of long-term heart rate variability. The data discussed here have been analyzed according to this method.

The magnitude of heart rate variability is dependent on the complex mechanisms regulating the cardiac pacemaker. The cardiac pacemaker is influenced by sympathetic and parasympathetic nerves with centers in the brain stem and spinal cord whose activity is modified by impulses originating from the higher brain centers (8). Clinical conditions or drugs affecting cardioregulatory centers produce recognizable changes in the heart rate variability. General anesthesia at the stage of medullary paralysis will cause the heart rate to lose its variability (20). Severe respiratory distress syndrome of premature infants produces loss of heart rate variability (16). The present study demonstrates increase in both beatto-beat and long-term baseline heart rate variability with advancing gestational age of the newborn infant. Furthermore, it demonstrates that cardiac variability should be measured in relation to the state of sleep of the healthy neonate. It is generally agreed that increased variability of heart rate occurs in AS (4). In the present study, however, it was found that a significant increase only in long-term heart rate variability (II) and no change in beatto-beat heart rate variability in AS in comparison with QS. 
Computer analysis of respiratory rate of healthy full term infants has revealed random breath-to-breath interval variation (16). In the present study, the two indices of respiratory rate variability, namely, breath-to-breath respiratory variability and percent duration of apnea was significantly greater in AS in comparison with QS $(2,3)$. The maturational effect on respiratory variability, however, was only obvious on the duration of apnea that was significantly less in the full term infant in comparison with premature infants.

Baseline heart rate and respiratory rate were lower in mature newborn infants. However, contrary to some reports in the literature $(2,7,17)$, no significant difference in baseline heart rate and respiratory rate between AS and QS was found. This is consistent with the findings of Hoppenbrouwers and Sterman (6) in young kittens.

It is of interest to note that the sharpest decrease in baseline heart rate and increase in indices of heart rate variability occurred between 32-36 wk of gestation when rapid functional and structural maturation of the central nervous system takes place (12). It may also be physiologically significant that the greatest decrease in percent apnea occurred at a later state of development (beyond $36 \mathrm{wk}$ of gestation). From the present study, it is clear that in newborn infants, variations in respiration and heart rate could only be evaluated in conjunction with sleep states. This was apparent even during relatively short periods monitoring employed in the present study.

\section{CONCLUSION}

The effect of gestational age and sleep state on heart rate and respiratory rate and their variability was evaluated in 32 neonates. With increasing maturity, cardiac and respiratory rates decreased. Heart rate variability was less before 34 wk gestational age, whereas, apnea frequency decreased significantly beyond $36 \mathrm{wk}$. Rates were not influenced by sleep state, but long-term cardiac variability, respiratory variability, and apnea frequency were significantly reduced in QS.

\section{REFERENCES AND NOTES}

1. Dawes, G. S.. Fox, H. E., Leduc, B. M., Liggin, G. C., and Richards, R. C. Respiratory movements and rapid eye movement sleep in the foetal lamb. $J$. Physiol., 220: 119 (1972).

2. Finer, N. N., Abrams. I. F., and Toeusch. H. E.: Ventilation and sleep states in newborn infants. J. Pediatr., 89: 100 (1976).

3. Gould, J. B., Lee. A. F. S., James, O., et al: The sleep state characteristics of apnea during infancy. Pediatrics, 59: 182 (1977).

Copyright (C) 1979 International Pediatric Research Foundation, Inc. $0031-3998 / 79 / 1310-1163 \$ 02.00 / 0$
4. Harper, R. M.. Hoppenbrouwers, K.. Sterman, M. B.. et al: Polygraphic studies of normal infants during the first 6 months of life. I. Heart rate and variability as a function of state. Pediatr. Res., 10: 945 (1976).

5. Hon, E. H.: Biophysical intrapartal fetal monitoring. In: Nesbit. R. E. L.: Clinics of Perinatology p. 149 (Philadelphia, W. B. Saunders Company, 1974).

6. Hoppenbrouwers, T., and Sterman, M. B.: Development of sleep patterns in the kitten. Exptl. Neurol., 49: 8220838 (1975).

7. Khatri, I. M., and Freis, E. D.: Hemodynamic changes during sleep. J. Appl. Physiol., 22: 867 (1967).

8. Levy, M. N.: Sympathetic-parasympathetic interaction in the heart. Circ. Res.. 29: 437 (1971).

9. Martin, C. B.. Siassi, B., and Hon, E. H.: Fetal heart rate patterns and neonatal death in low birth weight infants. Obstet. Gynecol., 44: 503 (1974).

10. Miller, H. C., Behrle, F. D., and Smull, N. W.: Severe apnea and irregular respiratory rhythms among premature infants: A clinical and laboratory study. Pediatrics, 23: 676 (1959).

11. Parmelee, A. H., and Stern, E.: Development of states in infants. In: Clemente. C., Purpura, D.. and Mayer, F. E.: Sleep and the Maturing Nervous System (Academic Press, New York, 1972).

12. Parmelee, A. H., Stern, E., and Harris, B. S.: Maturation of respiration in prematures and young infants. Neuropaediatrie, 3: 294 (1972).

13. Paul, R. H., and Hon, E. H.: Clinical fetal monitoring. V. Effect on perinatal outcome. Am. J. Obstet. Gynecol., I18: 529 (1974)

14. Prechtl, H. F. R.: Polygraphic studies of the fullterm newborn infant. II. Computer analysis of the recorded data. In: Bax. M.. and MacKeith. R.: Studies in Infancy. Clinics in Develop. Med. 27. pp. 26-40 (Heinemann, London. 1968).

15. Prechtl. J. F. R.: The behavioral states of the newborn infant (A Review) Brain Res., 76: 185 (1974)

16. Rudolph. A. J., Valbona, C., and Desmond, M. M.: Cardio-dynamic studies in the newborn. Ill. Heart rate patterns in infants with idiopathic respiratory syndrome. Pediatrics, 36: 554 (1965).

17. Snyder, F., Hobson, J. A., Morrison, D. F., and Goldfrank, F.: Changes in respiration, heart rate and systolic blood pressure in human sleep. J. Appl. Physiol., 19: 417 (1964).

18. Tarlo, P. A.. Valimski, I., and Rautaharju, P. M.: Quantitative computer analysis of cardiac and respiratory activity in newborn infants. J. Appl. Physiol.. 31: 70 (1971).

19. Valimaki, I.: Tape recordings of the electrocardiogram in newborn infants. Acta Pediat. Scand., (Suppl): 199 (1969).

20. Valbona, C., McCrady, J. D., and Hoff. H. E.: Neuro pharmacological factors influencing the central regulation of the respiratory heart rate response (RHR). Arch. Int. Pharmacodyn., 153: 256 (1965).

21. Valbona, C. Rudolph. A. J., and Desmond, M. M.: Cardiodynamic studies in the newborn. IV. Heart rate patterns in the nondistressed premature infant. Pediatrics, 36: 560 (1965).

22. Yeh, S. Y., Forsythe, A., and Hon, E. H.: Quantification of fetal heart beat-tobeat interval differences. Obstet. Gynecol., 41: 355 (1973).

23. The present address of Dr. B. Siassi is Queen Pahlavi Heart Hospital, Shahanshai Park, Teheran. Iran.

25. Requests for reprints should be addressed to: Joan E. Hodgman. M. D. Women's Hospital, 1240 N. Mission Road, Los Angeles, CA 90033 (USA).

24. This research was supported, in part, by HEW. Maternal and Child Health and Crippled Children Services grant MC-R-060228-02-0 and the Investigation Group Support of the Los Angeles County Heart Association, grant number $4711 \mathrm{G} 3$.

26. Received for publication May 24, 1977.

27. Accepted for publication November 8,1978 